Int. J. Electrochem. Sci., 13 (2018) 3897 - 3909

\title{
Electrolytic Recovery of High Purity Zr from Radioactively Contaminated Zr Alloys in Chloride Salts
}

\author{
Sungjune Sohn ${ }^{1}$, Jaeyeong Park ${ }^{2, *}$, Il Soon Hwang ${ }^{1}$ \\ ${ }^{1}$ Department of Energy System Engineering, Seoul National University, 1 Gwanak-ro, Gwanak-gu, \\ Seoul 08826, Republic of Korea \\ ${ }^{2}$ School of Mechanical, Aerospace and Nuclear Engineering, Ulsan National Institute of Science and \\ Technology, 50 UNIST-gil, Ulju-gun, Ulsan 44919, Republic of Korea \\ *E-mail: jypark@unist.ac.kr
}

doi: $10.20964 / 2018.04 .56$

Received: 9 January 2018 / Accepted: 19 February 2018 / Published: 6 March 2018

\begin{abstract}
It has been believed that high purity $\mathrm{Zr}$ metal is hard to be prepared from $\mathrm{Zr}$ alloys in $\mathrm{LiCl}-\mathrm{KCl}$ salts since $\mathrm{Zr}$ has various redox reactions in $\mathrm{LiCl}-\mathrm{KCl}$ including insoluble $\mathrm{ZrCl}$ formation and disproportionate reaction between $\mathrm{Zr}$ and $\mathrm{Zr}^{4+}$. We examined electrolytic $\mathrm{Zr}$ recovery from Zircaloy-4 by controlling anodic potential at five concentrations of $\mathrm{ZrCl}_{4}$ in $\mathrm{LiCl}-\mathrm{KCl}$ salts. Anode potential of $0.9 \mathrm{~V}$ (vs. $\mathrm{Ag} / \mathrm{AgCl}$ ) was applied to prevent the elements except $\mathrm{Zr}$ being dissolved from the anode into the electrolyte. Experimental results showed $\mathrm{Zr}$ with purity of over $99.9 \%$ was recovered and all alloying elements were analyzed below their detection limit in ICP-MS. In addition, at low $\mathrm{ZrCl}_{4}$ concentrations of 0.1 and $0.5 \mathrm{wt} . \%$, the chemical form of the cathode deposits was $\mathrm{Zr}$ metal without $\mathrm{ZrCl}$ while only $\mathrm{ZrCl}$ without $\mathrm{Zr}$ metal was recovered at the high $\mathrm{ZrCl}_{4}$ concentration, 2.0 and 4.0 wt.\%. At the $\mathrm{ZrCl}_{4}$ concentration of $1.0 \mathrm{wt} . \%$, both $\mathrm{Zr}$ metal and $\mathrm{ZrCl}$ were recovered. Therefore, preparation of high purity $\mathrm{Zr}$ metal from $\mathrm{Zr}$ alloys is feasible in $\mathrm{LiCl}-\mathrm{KCl}$ at low concentration of $\mathrm{ZrCl}_{4}$.
\end{abstract}

Keywords: Electrolytic recovery, Electrorefining, Zr recovery, High Purity Recovery, LiCl-KCl

\section{FULL TEXT}

(C) 2018 The Authors. Published by ESG (www.electrochemsci.org). This article is an open access article distributed under the terms and conditions of the Creative Commons Attribution license (http://creativecommons.org/licenses/by/4.0/). 